\title{
The financial cost of doctors emigrating from sub-Saharan Africa: human capital analysis
}

\author{
(c) $(1)(8)$ OPEN ACCESS
}

\author{
Edward J Mills chair of global health ${ }^{12}$, Steve Kanters statistician ${ }^{12}$, Amy Hagopian assistant \\ professor of global health ${ }^{3}$, Nick Bansback health economist ${ }^{4}$, Jean Nachega professor of medicine, \\ and director ${ }^{5}$, Mark Alberton research associate ${ }^{1}$, Christopher G Au-Yeung research assistant ${ }^{6}$, \\ Andy Mtambo research scientist ${ }^{6}$, Ivy L Bourgeault professor ${ }^{1}$, Samuel Luboga deputy dean, \\ education ${ }^{7}$, Robert S Hogg professor of health sciences ${ }^{68}$, Nathan Ford research associate ${ }^{9}$
}

${ }^{1}$ Faculty of Health Sciences, University of Ottawa, Ottawa, Canada K1N6X1; ${ }^{2}$ Centre for Evaluation and Clinical Epidemiology, Vancouver, Canada; ${ }^{3}$ Department of Global Health, School of Public Health, University of Washington, Seattle, USA; ${ }^{4}$ School of Population and Public Health, University of British Columbia, Vancouver, Canada; ${ }^{5}$ Centre for Infectious Diseases, Faculty of Health Sciences, University of Stellenbosch, Cape Town, South Africa; ${ }^{6}$ British Columbia Centre for Excellence in HIV/AIDS, Vancouver, Canada; ${ }^{7}$ Office of the Dean, School of Medicine, Makerere University, Kampala, Uganda; ${ }^{8}$ Faculty of Health Sciences, Simon Fraser University, Burnaby, Canada; ${ }^{9}$ Centre for Infectious Disease Epidemiology and Research, University of Cape Town, South Africa

\begin{abstract}
Objective To estimate the lost investment of domestically educated doctors migrating from sub-Saharan African countries to Australia, Canada, the United Kingdom, and the United States.

Design Human capital cost analysis using publicly accessible data. Settings Sub-Saharan African countries.

Participants Nine sub-Saharan African countries with an HIV prevalence of $5 \%$ or greater or with more than one million people with HIV/AIDS and with at least one medical school (Ethiopia, Kenya, Malawi, Nigeria, South Africa, Tanzania, Uganda, Zambia, and Zimbabwe), and data available on the number of doctors practising in destination countries.

Main outcome measures The financial cost of educating a doctor (through primary, secondary, and medical school), assuming that migration occurred after graduation, using current country specific interest rates for savings converted to US dollars; cost according to the number of source country doctors currently working in the destination countries; and savings to destination countries of receiving trained doctors.
\end{abstract}

Results In the nine source countries the estimated government subsidised cost of a doctor's education ranged from $\$ 21000$ ( $₹ 13000$; $€ 15000)$ in Uganda to $\$ 58700$ in South Africa. The overall estimated loss of returns from investment for all doctors currently working in the destination countries was $\$ 2.17 \mathrm{bn}$ (95\% confidence interval 2.13bn to $2.21 \mathrm{bn})$, with costs for each country ranging from $\$ 2.16 \mathrm{~m}$ (1.55m to $2.78 \mathrm{~m}$ ) for Malawi to $\$ 1.41 \mathrm{bn}$ (1.38bn to $1.44 \mathrm{bn}$ ) for South Africa. The ratio of the estimated compounded lost investment over gross domestic product showed that Zimbabwe and South Africa had the largest losses.
The benefit to destination countries of recruiting trained doctors was largest for the United Kingdom (\$2.7bn) and United States $(\$ 846 \mathrm{~m})$.

Conclusions Among sub-Saharan African countries most affected by HIV/AIDS, lost investment from the emigration of doctors is considerable. Destination countries should consider investing in measurable training for source countries and strengthening of their health systems.

\section{Introduction}

The migration of health workers from developing countries to developed ones is a well recognised contributor to weak health systems in low income countries and is considered a primary threat to achieving the health related millennium development goals. ${ }^{1}$ In 2010 the World Health Assembly unanimously adopted the first code of practice on the international recruitment of health personnel, which recognises problems related to the global shortage of health staff and calls for all countries to mitigate the negative effects from the migration of health workers. The code also calls on wealthy countries to provide financial assistance to source countries affected by the losses of health workers. ${ }^{2}$

The code is particularly important for sub-Saharan Africa where, according to the World Health Organization, the majority of countries are experiencing a critical shortage of doctors, nurses, and midwives. ${ }^{3}$ Many doctors from these countries have left to pursue better career opportunities in developed countries. ${ }^{4-12}$ The problem is exacerbated by the continent bearing the greatest burden of diseases such as HIV/AIDS. ${ }^{13}$ While Africa experiences $24 \%$ of the global burden of disease, it has only $2 \%$ 
of the global supply of doctors, and less than $1 \%$ of expenditures are on global health. ${ }^{114}$ Countries with a high prevalence of HIV are particularly affected by shortages of health workers for several reasons. Firstly, HIV has been documented as a leading cause of death among health workers-in the first five years of the AIDS epidemic, for example, an estimated 1 in 10 health workers in Malawi died of AIDS. ${ }^{15}$ Secondly, HIV leads to health workers' absenteeism owing to illness among staff or their relatives. ${ }^{16}$ Finally, the increased workload resulting from HIV/AIDS illness has not been met by a commensurate increase in staff, leading to increased burnout and fatigue. ${ }^{17}$

The shortage of doctors in most African countries is attributed to institutes lacking the capacity to train sufficient numbers of doctors, coupled with an inability to retain doctors, who choose to emigrate for what they consider better career

opportunities. ${ }^{18} 1920$ Many wealthy destination countries, which also train fewer doctors than are required, ${ }^{21}$ depend on immigrant doctors to make up the shortfall. In this way developing countries are effectively paying to train staff who then support the health services of developed countries. Although developed countries often provide development assistance to resource limited countries, the amount that goes into the training of health workers is variable and limited. ${ }^{22}$

Although the code of practice is voluntary, specific recommendations are to report data on the migration of health staff and to establish research programmes on migration. ${ }^{2}$ The ability of wealthy countries to produce such data is mixed as non-licensed health workers are often not counted. We estimated the monetary losses incurred by sub-Saharan African countries secondary to the migration of doctors licensed to practise in Australia, Canada, the United Kingdom, and the United States. These four destination countries were chosen because for more than 50 years they have benefited from the mass immigration of doctors. ${ }^{4}$ In the setting of HIV epidemics and related health problems, the loss of these vital members of society undermines both health and social stability in African communities.

Quantifying economic losses may help motivate and encourage policy makers to improve working conditions and incentive programmes to retain doctors in the countries where they were trained, and to support improvements in the infrastructure of medical training in sub-Saharan Africa.

\section{Methods}

We included data on doctors practising in Australia, Canada, the United Kingdom, and the United States who had received their medical education in a selected African country. As the concern about loss of doctors is related to the burden of disease in the countries left, we selected African states according to HIV rates, as determined by WHO, and included those that had an HIV prevalence of $5 \%$ or greater or more than one million residents with HIV/AIDS. We excluded countries with no medical schools or those with medical schools too new to have generated doctors.

\section{Data sources}

We accessed publicly available data. ${ }^{23}$ To estimate data on primary and secondary school spending we used Unesco data from two published reports on public expenditure for students in primary and secondary schools as a percentage of gross domestic product per capita. ${ }^{24}$ Data on gross domestic product were obtained from the United Nations and included the gross domestic product and gross domestic product per capita in current US dollars. ${ }^{24}$
The number of medical schools and contact information were identified through the Institute for International Medical Education website (a comprehensive database of international medical schools) and the sub-Saharan Africa Medical Schools Study. ${ }^{19}{ }^{25}$ For each country we obtained the costs of medical schools up to July 2011 through information posted on the medical school or university website. In the absence of available data for the largest medical university in a given country, we chose the largest with available data. University costs were gathered from the Addis Ababa University (Ethiopia), University of Nairobi (Kenya), University of Malawi (Malawi), Igbinedion University Okada (Nigeria), University of Stellenbosch (South Africa), Makerere University (Uganda), Hubert Kairuli Memorial University (Tanzania), University of Zambia (Zambia), and the University of Zimbabwe (Zimbabwe). When medical school costs subsidised by government were not available from our contacts for public universities, we used the costs from large not for profit private medical schools.

We obtained statistics on HIV prevalence (percentage in those aged 15-49) from the UNAIDS 2008 report on the global AIDS epidemic and the 2009 AIDS epidemic update. ${ }^{13}$ Data on the density of doctors was obtained from the WHO Global Health Observatory. ${ }^{26}$ Currency conversion was done through the XE universal converter website in July $2011 .{ }^{27}$ We derived data on the number of African trained doctors currently practising in the destination countries through communication with respondents at the Australian Medical Association (Masterfile), the Canadian Medical Association (Masterfile), the American Medical Association (Masterfile), and the UK General Medical Council (through an access to information request). All data were accurate up to September 2010.

We took the average age of retirement for doctors in the destination countries from various sources, including direct contact with the medical councils of the destination countries. ${ }^{28-31}$ The age distribution of active doctors for Australia, Canada, the United Kingdom, and the United States was taken from, respectively, the Australian Institute of Health and Welfare, the Canadian Medical Association, the British Medical Association and General Medical Council, and the American Medical Association, respectively. ${ }^{27}{ }^{32-34}$

We obtained the most recent interest rates on savings for each African country from the websites of their respective major national banks. Given the economic instability of Zimbabwe, we derived a conservative inflation rate from neighbouring countries. The average cost of medical education was obtained from the medical association of each destination country.

\section{Statistical analysis}

\section{Education costs}

Medical schools in sub-Saharan African countries tend to admit students directly from secondary (high) school into university programmes that last for five or six years. Typically, the first two years focus on the basic sciences and the remaining three on clinical medicine. Recently, some schools have begun to adapt their curriculums around health problems of national priority. ${ }^{19}$ Postgraduate specialty training varies widely from location to location, sometimes in the form of programmes at masters level. ${ }^{35} 36$

We estimated the total costs of government subsidised education through primary, secondary, and tertiary school. Because of inconsistencies in estimating these across countries and because several countries lack enough capacity for most doctors to obtain advanced training, we took the conservative course of not including costs for postgraduate education and training. 
To calculate the government cost of primary and secondary schooling within each country, we first calculated the cost for each year within each country. The costs for each school year, for primary and secondary school, were obtained by multiplying the gross domestic product per capita by the public expenditure for each pupil as a percentage of gross domestic product per capita:

public expenditure per student (primary or secondary)=gross domestic product (current $\$$ per capita) $\times$ (public expenditure per student, as \% of gross domestic product per capita)/100)

Finally, we calculated the total cost of primary and secondary school by multiplying the respective cost per year by the number of years spent at each school level. The number of years spent at each school level differs between countries. For example, Kenyan children spend eight years at primary school and four at high school, whereas Ugandan children spend seven and eight years, respectively. We accounted for this in the estimation process.

\section{Medical school costs}

Medical school costs were obtained in local currency and then converted to US dollars. We calculated the cost per year of medical education and accommodation, incorporating the differing years of programmes between states. We identified the costs for private tuition and calculated the state subsidised amounts. After calculating the costs of medical education to the governments in each of the nine countries, we calculated the average number of working years for doctors in each destination country, the average age at emigration for each source country, and the fixed deposit interest rate in each country.

\section{Average working years for doctors}

The average age that family and general practitioners retire is 63 years in Australia and the United Kingdom, 62 in Canada, and 64 in the United States. We applied these retirement ages to the African international medical graduates who emigrated to these countries. We conservatively set the age of migration at age $30 .{ }^{37}$ Therefore an African international medical graduate would work a maximum of 33 years in Australia and the United Kingdom, 32 in Canada, and 34 in the United States. Thus by using data on the age distribution of doctors by age category $(<35,35-44,45-54,55-64, \geq 65$, unknown age) for Australia, Canada, the United Kingdom, and the United States, we determined the average number of working years for each age group of African international medical graduates currently practising in the four destination countries. To calculate the value for the unknown age category, we averaged the number of working years from the age groups. We carried out a sensitivity analysis that assumed workers had remained working in their source country for a further 7.2 years. ${ }^{38}$

\section{Lost returns on investment}

To calculate the lost returns on investment for source countries when a doctor emigrates, we multiplied the total cost of educating a doctor by a compounding factor. ${ }^{39}{ }^{40}$ In algebraic terms, the lost return from a government's investment in the education of a doctor who eventually emigrates to a destination country would be:

\section{$\mathrm{LR}=\mathrm{EC}(1+\mathrm{r})$}

where LR is the lost return on investment, EC is the cost of a doctor's education, and $(1+r)^{t}$ is the annual compound factor for interest. Within the compounding factor, $r$ is the interest rate for a fixed savings deposit and $t$ is the time from start of investment. The formula gives the future value of the investment lost in $\mathrm{t}$ years after educating a doctor-assuming the interest is compounded on a yearly basis. The time from start of investment is the average work life of the doctor, calculated as the difference between average retirement age (62-64) in each destination country and the average age at emigration from each of the 10 source countries. For each African country we calculated the lost return on investment for one emigrant doctor for each age category in each destination country. In turn, using the appropriate age distributions as well as the number of doctors working in the destination countries, we multiplied these costs by the estimated number of doctors in each category and summed, yielding the lost returns on investment.

\section{Calculating number of international medical graduates in the destination countries}

We calculated confidence intervals for the number of African educated doctors working in destination countries by multiplying the confidence intervals for the proportion of such doctors. The estimated proportion was obtained by dividing the reported number of doctors who emigrated to the destination countries by the total number of doctors in each sub-Saharan African country. The confidence intervals were then calculated using $\mathrm{Z}$ intervals for proportions. Using the upper and lower bounds of these confidence intervals we repeated the calculations for the lost returns on investment.

\section{Sensitivity analysis}

A sensitivity analysis was carried out in two steps by considering factors that reduce the estimated loss in investment, a best scenario, and its counterpart, the worst scenario. We obtained the best scenario estimate by reducing the years over which the principal is compounded, by reducing the public's cost in the case when students go to private schools and reducing medical school costs by removing non-tuition fees. The mean time from end of school to emigration is conservatively estimated as 7.2 years. ${ }^{38}$ We used a weighted average to account for the various ages of the doctors working abroad. Rather than use the midpoint of each age category to calculate the amount of time over which to compound, we used the extremity of the intervals to minimise the compounding time. Only Nigeria and Tanzania have private medical schools, so the number of doctors in these countries was reduced by the percentage of private medical schools. For the remaining countries, the cost of primary and secondary schools was reduced by the percentage of students attending private schools as reported by Unesco. The worst scenario compounds costs over the full length of a doctor's career using the deposit rate for each country (see web extra of data for our analyses).

\section{Results}

Full data were available for nine of 17 countries with prevalence thresholds for HIV/AIDS above $5 \%$ or with more than one million patients. Figure $1 \Downarrow$ shows the flow of countries through the study.

Table $1 \Downarrow$ displays important health indicators and statistics for the medical schools in the African source countries. South Africa, Nigeria, and Kenya had the largest number of people with HIV. South Africa had the highest density of doctors (8 per 10000 population), whereas Nigeria had the largest number of medical schools $(n=21)$.

Using country specific statistics on gross domestic products, the public expenditure on primary and secondary education for 
each student for primary schools ranged from $\$ 490.0$ (Zimbabwe) to $\$ 8448.5$ (South Africa) and for secondary schools ranged from $\$ 336.2$ (Ethiopia) to $\$ 9866.9$ (South Africa, table $2 \Downarrow$ ).

Table $3 \Downarrow$ shows the estimated government subsidised tuition costs for a doctor's education in the nine source countries. Medical school costs for each student were highest in South Africa (\$40 383), which also had the highest total education cost for each medical student ( $\$ 58698$ ). At the other end of the spectrum, Uganda had the lowest medical school costs $(\$ 18$ 870).

Table $4 \Downarrow$ shows the estimated compounded lost investment for each country, calculated using data on age distribution and number of African trained migrant doctors reported by the authorities in Australia, Canada, the United Kingdom, and the United States. The estimated loss of returns from investment for all doctors working in the destination countries was $\$ 2.17 \mathrm{bn}$ (95\% confidence interval $2.13 \mathrm{bn}$ to $2.21 \mathrm{bn}$ ). Table 4 shows the costs for each country. These ranged from $\$ 2.16 \mathrm{~m}$ for Malawi ( $1.55 \mathrm{~m}$ to $2.78 \mathrm{~m}$ ) to $\$ 1.41 \mathrm{bn}$ for South Africa (1.38bn to $1.44 \mathrm{bn})$.

\section{Relative burden on health systems}

The estimated compounded lost investment for South Africa, accounting for more than $50 \%$ of the estimated compounded lost investment for all nine countries, was much larger than that observed in the other countries. Figure $2 \Downarrow$ displays the loss in relative terms. The size of each bubble represents the ratio of the estimated compounded lost investment over gross domestic product. From this perspective, Zimbabwe and South Africa seem to have the largest losses. The y axis corresponds to the ratio of (domestically trained) doctors working abroad in the target countries and those currently working domestically. Ethiopia, Zambia, and South Africa faired the worst.

\section{Sensitivity analysis}

Table $5 \Downarrow$ shows the results for the sensitivity analysis. Applying the best scenario assumption, the conditions decreased the estimated investment costs to $\$ 1.41 \mathrm{bn}$. Compounding over the full length of a doctor's career and using the deposit rate for each country (the worst scenario) led to substantial increases in investment loss. Half the estimated losses increased by more than 10-fold. In absolute numbers, South Africa had the largest change, from $\$ 1.41 \mathrm{bn}$ to $\$ 9.76 \mathrm{bn}$. In total the countries would have lost \$13.53bn.

\section{Savings in destination countries from recruited doctors}

Destination countries do not have to provide medical school training to doctors who successfully pass licensing examinations. Therefore destination countries benefit from not having trained recruited doctors. Based on the number of doctors working from the nine source countries and the average cost of medical education in these countries, this equals a saving of at least $\$ 621 \mathrm{~m}$ for Australia, $\$ 384 \mathrm{~m}$ for Canada, $\$ 2.7 \mathrm{bn}$ for the United Kingdom, and $\$ 846 \mathrm{~m}$ for the United States; $\$ 4.55 \mathrm{bn}$ in total. As the United Kingdom had the largest number of African doctors practising, its savings were the largest.

\section{Discussion}

Ethiopia, Kenya, Malawi, Nigeria, South Africa, Uganda, Tanzania, Zambia, and Zimbabwe have lost more than \$2bn from training doctors who then migrated to one of the four developed countries: Australia, Canada, United Kingdom, United States. Medical education is typically highly subsidised by the public sector in African nations, with more than half of the medical schools in sub-Saharan Africa either offering free tuition or charging less than $\$ 1000$ yearly. ${ }^{8}{ }^{19}$ At the same time, destination countries have saved billions of dollars in training costs by recruiting doctors who have been trained abroad. As international efforts are focusing on strengthening health systems, the development of human resources should be a core component of support from developed nations.

\section{Strengths and weaknesses of the study}

Our study has several strengths and limitations. Strengths included the use of conservative estimates of costs and lost investments compared with interest rates often reported by differing international financial institutions; we chose interest rates on the lower end of available data to avoid the overestimation of lost investments. When, for example, we applied a sensitivity analysis examining deposit rates, the lost investment increased to over $\$ 10 \mathrm{bn}$. We do not know the number of doctors who emigrated to the destination countries but never entered medical practice nor did we quantify the number of doctors practising outside the four destination countries in settings such as Saudi Arabia, a popular destination for new graduates. Both of these limitations may result in underestimates of the true loss to the source countries under study. However, we did not consider the number of doctors who return to their source countries nor examine the benefits of doctors sending financial resources back to families in the home countries. While these factors may mitigate the losses, little is known about how widespread or systematic they may be. Remittance by all professionals to sub-Saharan Africa in 2010 is estimated at $\$ 21.5 \mathrm{bn}$, a growth of $5.5 \%$ from the previous year. ${ }^{41} \mathrm{~A}$ recent survey estimated that doctors typically remit $\$ 4500$ yearly to their source countries. ${ }^{38}$ Remittances typically go to family members rather than the state and so it is impossible to quantify the impact of remittances on the local economy.

To the best of our ability we assessed whether education in the source countries is government supported, private, or a combination of the two, but recognise that this may change over differing time periods and differing governments. For example, Uganda has recently changed its public university coverage to focus solely on science, thereby increasing the number of medical school attendees with government coverage. Our study assumes that students go directly from secondary school to medical school and does not account for those who have received previous medical training, including former nurses and clinical officers. We used the current gross domestic product as a proxy of costs for primary and secondary schools. Gross domestic product in sub-Saharan African countries has fluctuated over the past four decades and it is possible that a different gross domestic product would alter our study findings for pre-university education. Finally, although confidence intervals are provided, these assume a fixed interest rate through time. Given the current poor economic climate, these results are conservative and we acknowledge a higher degree of variance.

\section{Comparison with other studies}

Three previous studies attempted to quantify the economic value of losing health staff, but these analyses were limited to particular countries (Ghana, Kenya, and Malawi). ${ }^{39} 4042$ Other studies found that doctors typically migrate from African countries to more developed countries-namely, Australia, Canada, the United Kingdom, and the United 
States $^{4} 12184344$-but do not attempt to quantify the economic implications of such migration patterns. Our study focused on the direct costs of educating doctors in the source countries. Additional economic costs to the loss of doctors from these source countries occur, including the lost investment on the education of other health workers. A previous analysis that examined a case study of only Ghanaian doctors in the United Kingdom estimated a saving in current training cost to the United Kingdom of about $£ 65 \mathrm{~m}$ from the employment of 293 Ghanaian doctors working in $2004 .^{42}$ A recent survey of African doctors working in Canada and the United States showed that most doctors emigrate immediately after training, but, when considering all respondents to the survey, the average number of years working in the source countries was 7.2. ${ }^{38}$ The author implies that during this period doctors may have already repaid their debt to the source country. ${ }^{45}$ Many of the countries we surveyed employ a lower cadre of health workers for many common health provisions, including the care of people with HIV/AIDS, including non-doctor clinicians, ${ }^{46}$ nurses,${ }^{47}$ and community health workers. ${ }^{48}$ Other notable economic issues relevant to the lost investment in doctors include the lack of specialised medical care available and the morbidity and mortality associated with it. Although our study examined only doctors, the emigration of nurses and pharmacists from the source countries has also been important. We also recognise that developing countries experience an out-migration of health workers to other developing countries, and future research should attempt to estimate losses in other regions.

\section{Possible mechanisms and implications for clinicians or policy makers}

The new code of practice on the international recruitment of health personnel suggests that source and destination countries could benefit by crafting bilateral agreements that acknowledge the transfer of staff from developing countries to developed ones, and provide technical assistance and other support to countries that are losing trained health professionals. Our study highlights that the loss to developing countries is substantial and that any compensation should be more than token: the lost return on investments in medical education is one way to attach a value to the amount of technical or other compensatory assistance that recipient countries should provide. In 2008, the United States' President's Emergency Plan for AIDS Relief (PEPFAR) re-authorisation legislation recognised the need to build an infrastructure for health workers and committed to the expansion of medical training and research capabilities through African academic centres, by contributing $\$ 130 \mathrm{~m}$ to improve and achieve large numbers of health staff over the next five years. ${ }^{49}$ Contributions from Australia, Canada, and the United Kingdom to medical education have been substantially lower. ${ }^{50-52}$

Our results indicate that South Africa incurs the highest costs for medical education and the greatest lost returns on investment for all doctors currently working in destination countries. These findings are supported by statistics on human health resources. South Africa has the highest density of doctors per population. However, the distribution of doctors in South Africa is unbalanced and there is a 14-fold difference in density of doctors between urban and rural settings. ${ }^{17}$ Previous estimates indicate that up to $30 \%$ of South African doctors have emigrated to the destination countries we examined, many during apartheid. ${ }^{53}$ In addition, interviews with health workers revealed that $58 \%$ were intending to emigrate to these countries..$^{53}$ Thus, South Africa, although producing a large number of doctors, also loses the most to developed countries. Conservative estimates indicate that South Africa requires three times its current workforce to meet the requirements of providing care for AIDS. ${ }^{54}$ Any future approaches to improving the numbers of doctors will need to recognise that additional educational opportunities may lead to additional lost investments.

\section{Unanswered questions and future research}

Previous research has focused on the number of health workers working in the destination countries ${ }^{41244}$ and on the ethics of recruitment of health staff. ${ }^{55-58}$ Less research has examined the impact of the density of health workers on morbidity and mortality in the source countries. With a new emphasis on strengthening health systems by major international donors, questions are arising about what investments should be made to strengthen a health system and what measures should be used to determine the strength of a health system. Canada, the United Kingdom, and the United States have clearly stated that maternal and child health will be the focus of present investments, steering away from disease specific investments such as HIV/AIDS. ${ }^{59}$ There is a clear need to recognise that measuring the effectiveness of a health system is a complex endeavour that may result in unclear findings. The support for education and retention of health staff represents one major way to ensure that general and specialty healthcare are available in these source countries. With the exception of the United States, our chosen destination countries have not targeted medical or health training as a focused supportive role. Recent studies have indicated that although the capacity for medical education is expanding in Africa, substantial support is needed to improve weaknesses in infrastructure and that retention strategies need to be developed to reinforce the number of teaching staff, who are also among those medical staff who emigrate. ${ }^{19}$

\section{Conclusions}

Countries in sub-Saharan Africa are losing considerable investments in medical education through the emigration of doctors to wealthier destination countries. The new voluntary code urges the government, private agencies, and non-government agencies that benefit from the immigration of doctors to increase their technical and financial support to enhance the strengthening of health systems in developing countries with critical shortages in health workforce. Efforts to increase support can include training, financial compensation, and population specific interventions. These should be commensurate with the benefits enjoyed by recipient countries.

We thank Peter Arnold (Australian Medical Council) for access to data; Meredith Fordyce and Mark Doescher (Department of Family Medicine Research Section, University of Washington) for access to data on African medical graduates practising in the United States; and Niyi Awofeso, Ike Anya, Eben Mouton, and Jimmy Volmink for access to country costs. EJM is supported by a Canada Research Chair from the Canadian Institutes of Health Research. IB is supported by a ClHR-Health Canada Research Chair in Health Human Resources Policy. JN is supported through a National Institutes of Health mentored patient oriented research career award (K23 Al068582-01).

Contributors: EJM and NF conceived the study. EJM, CGA-Y, MA, NF, ILB, NB, and AH designed the study. EJM, AH, JN, CGA-Y, MA, AM, and SK identified the data and obtained the data. SK carried out the statistical analysis. NF, RSH, NB, and EJM supervised the project. CGA-Y, MA, AM, ILB, NF, AH, SL, and EJM prepared the first draft of the manuscript. All authors revised the manuscript for important intellectual content. All authors approved the final version for publication. EM will act as guarantor. 


\section{What is already known on this topic}

A lack of adequately trained health workers contributes to weakened health systems

African doctors frequently emigrate for better opportunities

The impact of doctors' emigration on investments in the health system of individual countries is unknown

\section{What this study adds}

Among the nine sub-Saharan African countries most affected by HIV/AIDS, more than $\$ 2 \mathrm{bn}$ of investment was lost through the emigration of trained doctors

South Africa and Zimbabwe had the greatest economic losses from such emigration

Australia, Canada, the United Kingdom, and the United States benefit importantly from the recruitment and licensure of doctors educated elsewhere

Funding: This study received no direct funding. No funding agency has seen this study.

Competing interests: All authors have completed the ICMJE uniform disclosure form at www.icmje.org/coi_disclosure.pdf (available on request from the corresponding author) and declare: no support from any organisation for the submitted work; no financial relationships with any organisations that might have an interest in the submitted work in the previous three years; and no other relationships or activities that could appear to have influenced the submitted work. JN and SL work at universities that have received Medical Education Partnership Initiatives (MEPI) funding from the President's Emergency Plan for AIDS Relief.

Ethical approval: This study was approved by the University of British Columbia. No informed consent was required as no patients were enrolled and only secondary data were used.

Data sharing: The technical appendix, statistical code, and dataset are available from the corresponding author at Edward.mills@Uottawa.ca.

1 Scheffler RM, Liu JX, Kinfu Y, Dal-Poz M. Forecasting the global shortage of physicians: an economic- and needs-based approach. Bull World Health Organ 2008:86:516-23.

2 World Health Organization. WHO global code of practice on the international recruitment of health personnel. 2010. http://my.ibpinitiative.org/?syla573d.

World Health Organization. The world health report. WHO, 2006.

4 Mullan F. The metrics of the physician brain drain. N Engl J Med 2005;353:1810-8.

5 Chen LC, Boufford JI. Fatal flows-doctors on the move. N Engl J Med 2005;353:1850-2.

6 Eastwood JB, Conroy RE, Naicker S, West PA, Tutt RC, Plange-Rhule J. Loss of health professionals from sub-Saharan Africa: the pivotal role of the UK. Lancet 2005;365:1893-900

7 Hagopian A, Ofosu A, Fatusi A, Biritwum R, Essel A, Gary Hart L, et al. The flight of physicians from West Africa: views of African physicians and implications for policy. Soc Sci Med 2005;61:1750-60.

8 Hagopian A, Thompson MJ, Fordyce M, Johnson KE, Hart LG. The migration of physicians from sub-Saharan Africa to the United States of America: measures of the African brain drain. Hum Resour Health 2004;2:17.

9 Bundred PE, Levitt C. Medical migration: who are the real losers? Lancet 2000;356:245-6.

10 Pang T, Lansang MA, Haines A. Brain drain and health professionals. BMJ 2002;324:499-500.

11 Mullan F. Doctors and soccer players-African professionals on the move. N Engl J Med 2007;356:440-3.

12 Connell J, Zurn P, Stilwell B, Awases M, Braichet JM. Sub-Saharan Africa: beyond the health worker migration crisis? Social Sci Med 2007;64:1876-91.

13 UNAIDS. 2008 report on the global AIDS epidemic. UNAIDS, 2008.

14 Médecins Sans Frontières. Help wanted: confronting the health care worker crisis to expand access to HIV/AIDS treatment: MSF experience in southern Africa. 2007. www. doctorswithoutborders.org/publications/reports/2007/healthcare_worker_report_05-2007. pdf.

15 Harries AD, Hargreaves NJ, Gausi F, Kwanjana JH, Salaniponi FM. High death rates in health care workers and teachers in Malawi. Trans R Soc Trop Med Hyg 2002;96:34-7.

16 Huddart J, Picazo O. The health sector human resource crisis in Africa: an issues paper. United States Agency for International Development, Bureau for Africa, Office of Sustainable Development, 2003

17 Bedelu M, Ford N, Hilderbrand K, Reuter $\mathrm{H}$. Implementing antiretroviral therapy in rural communities: the Lusikisiki model of decentralized HIV/AIDS care. $J$ Infect Dis 2007;196(suppl 3):S464-8.

18 Hagopian ATM, Fordyce M, Johnson K, Hart G. The flight of physicians from West Africa: views of African physicians and implications for policy. Soc Sci Med 2005;61:1750-60.

19 Mullan F, Frehywot S, Omaswa F, Buch E, Chen C, Greysen SR, et al. Medical schools in sub-Saharan Africa. Lancet 2011;377:1113-21.

20 Mullan F. Some thoughts on the white-follows-green law. Health Aff (Millwood) 2002;21:158-9.

21 Pond B, McPake B. The health migration crisis: the role of four Organisation for Economic Cooperation and Development countries. Lancet 2006;367:1448-55.

22 Ravishankar N, Gubbins P, Cooley RJ, Leach-Kemon K, Michaud CM, Jamison DT, et al. Financing of global health: tracking development assistance for health from 1990 to 2007. Lancet 2009;373:2113-24.

23 BCCFE. Globally accumulated health indicator archive (GAIA). 2010. www.cfenet.ubc. ca/our-work/initiatives/gaia.
24 Unesco. Unesco Institute for Statistics. 2010. www.unesco.org/en/education.

25 Zachariah R, Spielmann MP. Chinii C, Gomani P, Arendt V, Hargreaves NJ, et al. Voluntary counselling, HIV testing and adjunctive cotrimoxazole reduces mortality in tuberculosis patients in Thyolo, Malawi. AIDS 2003;17:1053-61.

26 World Health Organization. Global Health Observatory. 2010. http://apps.who.int/ghodata/

27 American Medical Association. International medical graduates in American medicine: contemporary challenges and opportunities. AMA, 2010

28 Australian Doctor. Never say retire. 2006. www.australiandoctor.com.au/news/25/ 0c043525.asp.

29 Australian Age Pension. Australian retirement age. 2006. www.australiandoctor.com.au/ news/25/0c043525.asp.

30 Katz J. Issues of concern for the aging anesthesiologist. Anesth Analg 2001;92:1487-92.

31 Martin S. "Freedom 55" closer to age 65 for physicians. CMAJ 2000;163:1499.

32 Canadian Medical Association. Number of physicians by specialty and age, Canada, 2009. 2009. www.cma.ca/multimedia/CMA/Content_Images/Inside_cma/Statistics/historical/ 02SpecAge2009.pdf.

33 Australian Institute of Health and Welfare. Medical labour force 2007. 2009. www.aihw. gov.au/publications/index.cfm/title/10723.

34 British Medical Association. The UK medical workforce in 2008. 2010. www.bma.org.uk press_centre/pressmedicalworkforce.jsp.

35 Enright A. Anesthesia training in Rwanda. Can J Anaesth 2007;54:935-9.

36 Magoha GA, Ngumi ZW. Training of surgeons in Kenya at the University of Nairobi teaching hospital. East Afr Med J 1999;76:462-4.

37 Stilwell B, Zurn P, Connell J, Awases M. The migration of health workers: an overview. World Health Organization, 2005.

38 Clemons MA. The financial effects of high-skill emigration: new data on African physicians abroad. CGD working paper. Center for Global Development, 2011.

39 Kirigia JGA, Muthuri L, Nyoni J, Seddoh A. The cost of health professionals' brain drain in Kenya. BMC Health Serv Res 2006;6:89.

40 Muula A, Panulo B. Lost investment returns from the migration of medical doctors from Malawi. Tanzania Health Res Bull 2007;9:61-4.

41 The World Bank. Migration and development brief 16. 2011. http://siteresources.worldbank. org/EXTDECPROSPECTS/Resources/476882-1157133580628/ MigrationandDevelopmentBrief16.pdf.

42 Mensah K, Mackintosh M, Henry L. The "skills drain" of health professionals from the developing world: a framework for policy formulation. 2005. www.medact.org/content Skills\%20drain/Mensah\%20et\%20al.\%202005.pdf.

43 Onyebuchi AUO, Okeke C. Too poor to leave, too rich to stay: developmental aid global health correlates of physician migration to the United States, Canada, Australia, and the United Kingdom. Am J Public Health 2008;98:148-54.

44 Hagopian ATM, Fordyce M, Johnson K, Hart G. The migration of physicians from sub-Saharan Africa to the United States of America: measures of the African brain drain Hum Resour Health 2004;2:17.

45 Plaza S, Ratha D, Clemons M. Diaspora for development in Africa. World Bank, 2011

46 Mullan F, Frehywot S. Non-physician clinicians in 47 sub-Saharan African countries. Lancet 2007;370:2158-63.

47 Laurant M, Reeves D, Hermens R, Braspenning J, Grol R, Sibbald B. Substitution of doctors by nurses in primary care. Cochrane Database Syst Rev 2005;2:CD001271.

48 Lehmann U, Sanders D. Community health workers: what do we know about them? The state of evidence on programmes, activities, costs and impact on health outcomes of using community health workers. World Health Organization: Evidence and Information for Policy, 2007.

49 Medical Education Partnership Initiative (MEPI). 2010 www.fic.nih.gov/programs documents/mepi_factsheet.pdf.

50 DFID. Statistics on international development. 2010. www.dfid.gov.uk/Documents/ publications $1 /$ sid2010/SID-2010.pdf?epslanguage $=$ en

51 AusAID. Statistical summary 2005-2008. 2010. www.ausaid.gov.au/publications/pdf/ statsummary.pdf.

52 International Development and Research Canada. Annual report 2009-2010. 2010. www. idrc.ca/uploads/user-S/12833951541AR_09-10_ENG.pdf.

53 Awases M, Gbary A, Nyoni J, Chatora R. Migration of health professionals in six countries: a synthesis report. WHO Regional Office for Africa. 2004.

54 Barnighausen T, Bloom DE, Humair S. Human resources for treating HIV/AIDS: needs, capacities, and gaps. AIDS Patient Care STDS 2007;21:799-812.

55 Buchan J. Can the WHO code on international recruitment succeed? BMJ 2010;340:791-3.

56 Snyder J. Is health worker migration a case of poaching? Am J Bioeth 2009;9:3-7.

57 Mills EJ, Schabas WA, Volmink J, Walker R, Ford N, Katabira E, et al. Should active recruitment of health workers from sub-Saharan Africa be viewed as a crime? Lancet 2008;371:685-8.

58 Hagopian A. Recruiting primary care physicians from abroad: is poaching from low-income countries morally defensible? Ann Fam Med 2007;5:483-5.

59 Denny CC, Emanuel EJ. US health aid beyond PEPFAR: the Mother \& Child Campaign. JAMA 2008;300:2048-51.

Accepted: 23 September 2011 
Cite this as: BMJ 2011;343:d7031

This is an open-access article distributed under the terms of the Creative Commons Attribution Non-commercial License, which permits use, distribution, and reproduction in any medium, provided the original work is properly cited, the use is non commercial and is otherwise in compliance with the license. See: http://creativecommons.org/licenses/by$\mathrm{nc} / 2.0 /$ and http://creativecommons.org/licenses/by-nc/2.0/legalcode. 


\section{Tables}

Table 1| Statistics on health status and human resources in nine sub-Saharan African countries included in analysis

\begin{tabular}{|c|c|c|c|c|c|}
\hline Country & $\begin{array}{l}\text { HIV prevalence }(\%) \text { in } 15-49 \\
\text { year olds, } 2007\end{array}$ & $\begin{array}{c}\text { Estimated No of people* with } \\
\text { HIV }\end{array}$ & $\begin{array}{l}\text { Year of available data on } \\
\text { medical school costs }\end{array}$ & $\begin{array}{l}\text { No of medical } \\
\text { schools }\end{array}$ & $\begin{array}{c}\text { Doctors per } 10000 \\
\text { population }\end{array}$ \\
\hline Ethiopia & 2.1 & 1005000 & 2010 & 12 & $<1$ \\
\hline Kenya & 7.8 & 1750000 & 2010 & 3 & 1 \\
\hline Malawi & 11.9 & 930000 & 2009 & 1 & $<0.5$ \\
\hline Nigeria & 3.1 & 2600000 & 2009 & 25 & 3 \\
\hline South Africa & 16.9 & 5700000 & 2009 & 8 & 8 \\
\hline Tanzania & 5.7 & 1400000 & 2010 & 5 & $<0.5$ \\
\hline Uganda & 5.4 & 940000 & 2010 & 4 & 1 \\
\hline Zambia & 14.3 & 1100000 & 2009 & 1 & 1 \\
\hline Zimbabwe & 15.3 & 1300000 & 2009 & 2 & 2 \\
\hline
\end{tabular}

Data from UNAIDS 2010 update, sub-Saharan African Medical Schools Study, and World Health Report.

${ }^{*}$ Adults and children. 
Table 2| Expenditure on primary and secondary schools in nine sub-Saharan African countries, using the most recent year for which data were available

Expenditure per student

Country Year Primary school* Secondary school* ${ }^{\star}$ GDP (current $\$$ per capita) Year Primary school Secondary school

\begin{tabular}{|c|c|c|c|c|c|c|c|}
\hline Ethiopia & 2007 & 12.6 & 9.0 & 934.0 & 2008 & 941.5 & 336.2 \\
\hline Kenya & 2006 & 22.5 & 22.2 & 1573.0 & 2008 & 2831.4 & 1396.8 \\
\hline Malawi & 2003 & 10.2 & 21.6 & 794.0 & 2008 & 647.9 & 686.0 \\
\hline Nigeria & 2008 & 28.3 & 56.6 & 2203.0 & 2008 & 3740.7 & 7481.4 \\
\hline South Africa & 2008 & 13.7 & 16.0 & 10278.0 & 2008 & 8448.5 & 9866.9 \\
\hline Tanzania & 2007 & 22.9 & NA & 1400.0 & 2008 & 2165.8 & 1579.2 \\
\hline Uganda & 2009 & 7.3 & 21.2 & 1217.0 & 2008 & 621.9 & 1548.0 \\
\hline Zambia & 2005 & 5.5 & 7.8 & 1430.0 & 2008 & 550.6 & 669.2 \\
\hline Zimbabwe & 2001 & 14.0 & 21.0 & 500.0 & 2008 & 490.0 & 630.0 \\
\hline
\end{tabular}

$\mathrm{GDP}=$ gross domestic product; $\mathrm{NA}=$ not available.

${ }^{*}$ As percentage of GDP per capita. 


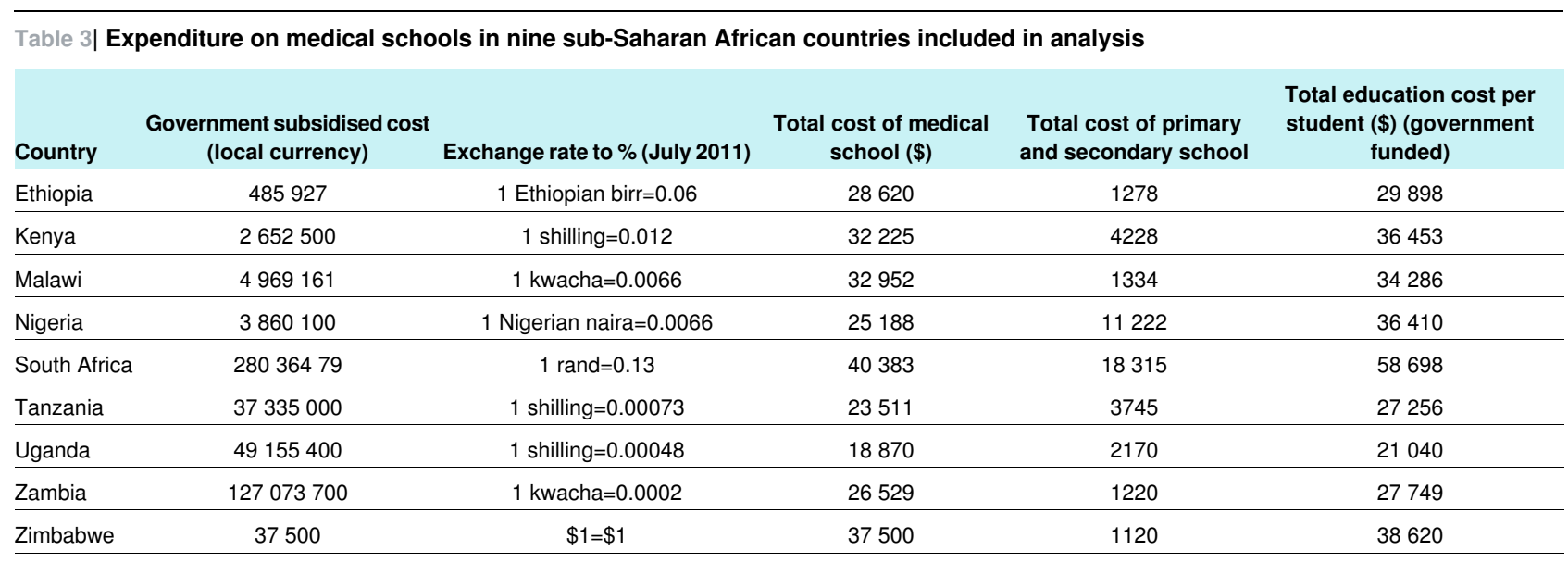


Table 4| Estimated lost investment from training doctors in nine high prevalence HIV countries who are currently practising in Canada, the United States, the United Kingdom, or Australia

\begin{tabular}{|c|c|c|c|c|c|c|}
\hline \multirow[b]{2}{*}{$\begin{array}{l}\text { Source } \\
\text { country }\end{array}$} & \multirow[b]{2}{*}{$\begin{array}{l}\text { Average } \\
\text { savings } \\
\text { interest } \\
\text { rate (\%) }\end{array}$} & \multirow[b]{2}{*}{ Destination country } & \multirow{2}{*}{$\begin{array}{l}\text { No of source } \\
\text { country doctors } \\
\text { in destination } \\
\text { countries }(95 \% \\
\text { Cl) }\end{array}$} & \multicolumn{3}{|c|}{ Estimated lost investment for source countries } \\
\hline & & & & $\begin{array}{c}\text { Per doctor in destination country (\$, } \\
\text { all age groups) }\end{array}$ & $\begin{array}{l}\text { Average per doctor } \\
\text { in destination } \\
\text { country }(\$)\end{array}$ & $\begin{array}{c}\text { All doctors in destination } \\
\text { countries }(\$, \text { millions }) \\
(95 \% \mathrm{Cl})\end{array}$ \\
\hline \multirow[t]{4}{*}{ Ethiopia } & \multirow[t]{4}{*}{1.80} & Canada & \multirow[t]{4}{*}{567 (526 to 608$)$} & 43752 & \multirow[t]{4}{*}{43394} & \multirow[t]{4}{*}{24.63 (22.85 to 26.40$)$} \\
\hline & & USA & & 43883 & & \\
\hline & & UK & & 37883 & & \\
\hline & & Australia & & 40589 & & \\
\hline \multirow[t]{4}{*}{ Kenya } & \multirow[t]{4}{*}{1.81} & Canada & \multirow[t]{4}{*}{328 (293 to 363 ) } & 53461 & \multirow[t]{4}{*}{50748} & \multirow[t]{4}{*}{16.75 (14.97 to 18.50$)$} \\
\hline & & USA & & 53623 & & \\
\hline & & UK & & 46253 & & \\
\hline & & Australia & & 49577 & & \\
\hline \multirow[t]{4}{*}{ Malawi } & \multirow[t]{4}{*}{2.75} & Canada & \multirow[t]{4}{*}{41 (2 to 53 ) } & 61926 & \multirow[t]{4}{*}{51238} & \multirow[t]{4}{*}{$2.16(1.55$ to 2.78$)$} \\
\hline & & USA & & 62412 & & \\
\hline & & UK & & 49722 & & \\
\hline & & Australia & & 55415 & & \\
\hline \multirow[t]{4}{*}{ Nigeria } & \multirow[t]{4}{*}{4.75} & Canada & \multirow{4}{*}{$\begin{array}{l}7106 \text { (7059 to } \\
7152)\end{array}$} & 104362 & \multirow[t]{4}{*}{89238} & \multirow[t]{4}{*}{654.27 (649.57 to 658.50$)$} \\
\hline & & USA & & 107001 & & \\
\hline & & UK & & 71757 & & \\
\hline & & Australia & & 87354 & & \\
\hline \multirow{4}{*}{$\begin{array}{l}\text { South } \\
\text { Africa }\end{array}$} & \multirow[t]{4}{*}{4.27} & Canada & $10822(10644$ to & 150273 & 127221 & 1412.70 (1382.51 to \\
\hline & & USA & & 153327 & & 1435.95) \\
\hline & & UK & & 107178 & & \\
\hline & & Australia & & 127669 & & \\
\hline Tanzania & 2.60 & Canada & 81 (65 to 97$)$ & 47600 & 44616 & 3.49 (2.81 to 4.17 ) \\
\hline & & USA & & 47930 & & \\
\hline & & UK & & 38676 & & \\
\hline & & Australia & & 42831 & & \\
\hline Uganda & 2.36 & Canada & 409 (371to 447) & 34830 & 32926 & $13.61(12.31$ to 14.85$)$ \\
\hline & & USA & & 35024 & & \\
\hline & & UK & & 28843 & & \\
\hline & & Australia & & 31622 & & \\
\hline Zambia & 4.00 & Canada & 206 (181 to 231 ) & 66703 & 57412 & 12.14 (10.68 to 13.58 ) \\
\hline & & USA & & 67889 & & \\
\hline & & UK & & 48574 & & \\
\hline & & Australia & & 57164 & & \\
\hline Zimbabwe & $5.1^{*}$ & Canada & 380 (344 to 416$)$ & 120295 & 101440 & 39.61 (35.87 to 43.27$)$ \\
\hline & & USA & & 123804 & & \\
\hline & & UK & & 80555 & & \\
\hline & & Australia & & 99650 & & \\
\hline
\end{tabular}


Table 5| Sensitivity analysis of estimated lost investment using variations on time working in destination countries, interest rates, and cost of education

\begin{tabular}{|c|c|c|c|}
\hline \multirow[b]{2}{*}{ Source country } & \multicolumn{3}{|c|}{ Estimated lost investment for source countries (\$, millions) } \\
\hline & All doctors from source countries & $\begin{array}{l}\text { Assuming later emigration and attendance at } \\
\text { private schools }\end{array}$ & $\begin{array}{l}\text { Compounding over full length of career and using } \\
\text { deposit rate }\end{array}$ \\
\hline Ethiopia & 24.63 & 21.76 & 260.32 \\
\hline Kenya & 16.75 & 11.89 & 59.02 \\
\hline Malawi & 2.16 & 1.40 & 5.15 \\
\hline Nigeria & 674.26 & 387.14 & 2297.82 \\
\hline South Africa & 1412.70 & 960.88 & 9764.50 \\
\hline Tanzania & 3.49 & 0.48 & 68.36 \\
\hline Uganda & 13.61 & 8.33 & 103.97 \\
\hline Zambia & 12.14 & 9.37 & 276.42 \\
\hline Zimbabwe & 39.61 & 23.14 & 699.17 \\
\hline
\end{tabular}




\section{Figures}

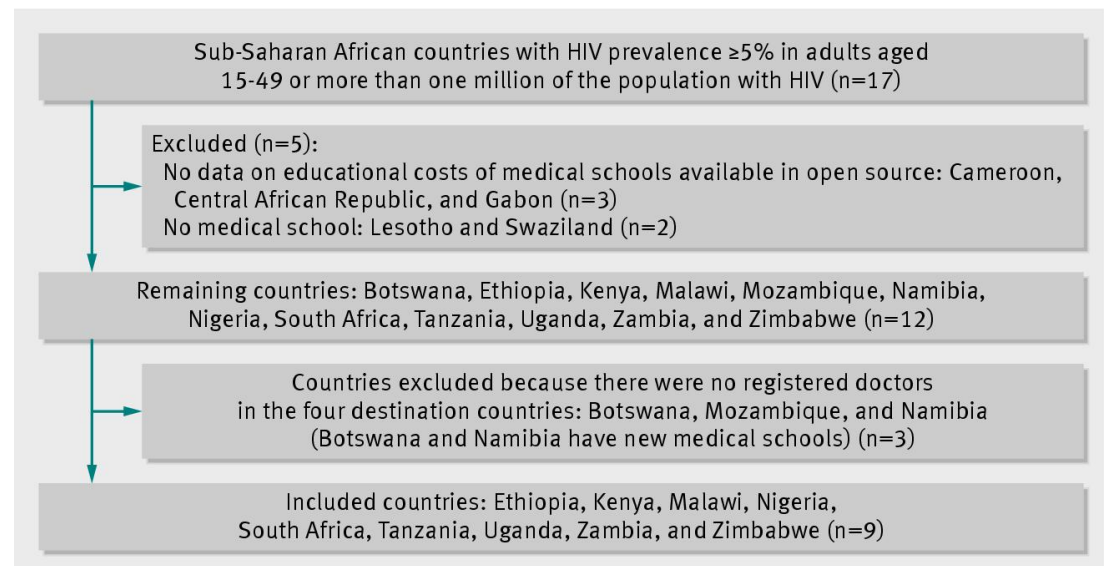

Fig 1 Flow of countries through study

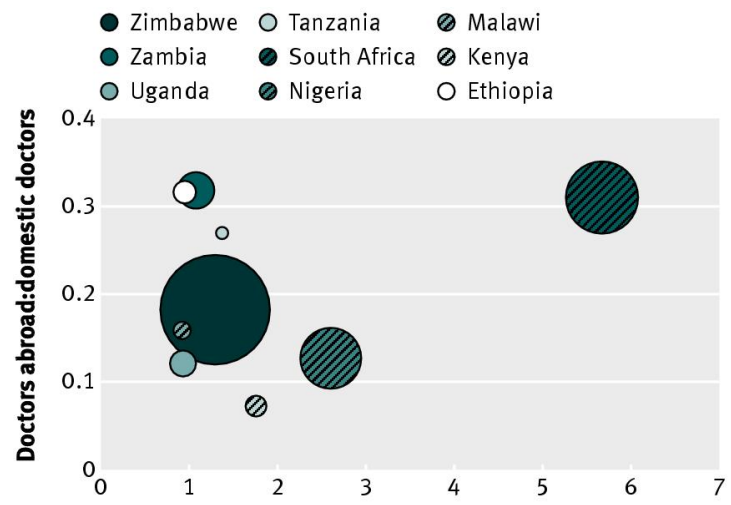

Estimated No of people with HIV (millions)

Fig 2 Loss of doctors to destination countries, compared with burden of HIV in nine African source countries. Size of each bubble represents ratio of estimated compounded lost investment over gross domestic product, and y axis corresponds to ratio of doctors working in target countries and doctors currently working domestically 